\title{
A construção dos dados de argumentos em uma Sequência Didática Investigativa em Ecologia
}

\author{
The construction of the data of arguments \\ in a Investigative Didactic Sequence in Ecology
}

Sofia Valeriano Silva Ratz ${ }^{1}$. Marcelo Tadeu Motokane ${ }^{2}$

\begin{abstract}
Resumo: Este trabalho parte da análise das interações discursivas e da argumentação e sua relação com o ensino de ciências. O objetivo é analisar quais os aspectos epistêmicos na construção dos dados de argumentos a partir de dados fornecidos pelo material didático. Utilizamos o modelo de Toulmin para identificarmos o argumento em uma Sequência Didática Investigativa em Ecologia, que aplicamos com professores em um curso de curta duração. Aplicamos dois sistemas de categorias nos episódios - as Práticas Epistêmicas e os Movimentos Epistêmicos - para analisarmos os aspectos epistêmicos desse processo. Os resultados indicam que há diferenciação dos aspectos epistêmicos de episódios que apresentam dados fornecidos com suportes teóricos mais simples daqueles mais complexos. Assim, dados fornecidos gerais demandam menor quantidade de Movimentos Epistêmicos e de Práticas Epistêmicas. Já os dados fornecidos específicos requerem do formador uma maior diversidade de Movimentos Epistêmicos e Práticas Epistêmicas, pelos professores.
\end{abstract}

Palavras-chave: Movimentos epistêmicos. Práticas epistêmicas. Argumentação. Ensino de ciências.

\begin{abstract}
This work is part of the analysis of discursive interactions and arguments and their relationship with the teaching of the sciences. The goal is to analyze the epistemic aspects in the construction of the arguments about data from the didactic material. We used the model of Toulmin to identify the arguments in an Investigative Didactic Sequence in Investigative Ecology that we apply to teachers on a short course. We applied two systems of categories in the episodes - epistemic practices and epistemic moves - to analyze the epistemic aspects of this process. The results indicate that there is a differentiation of epistemic aspects of episodes. Data provided with theoretical supports are simpler. Thus, data provided generally demands a lower quantity of epistemic moves and of epistemic practices. Specific data provided by the trainer requires a greater diversity of epistemic moves and epistemic practices by teachers.
\end{abstract}

Keywords: Epistemic moves. Epistemic practices. Argumentation. Science teaching.

\footnotetext{
${ }^{1}$ Universidade de São Paulo (USP), Programa de Pós-graduação Interunidades em Ensino de Ciências, São Paulo, SP, Brasil. E-mail: <sofiaratz@gmail.com>.

${ }^{2}$ Universidade de São Paulo (USP), Faculdade de Filosofia Ciências e Letras de Ribeirão Preto, Departamento de Biologia, Ribeirão Preto, SP, Brasil.
} 


\section{Os aspectos epistêmicos da argumentação}

Para propor o estudo das práticas sociais de construção de conhecimento, Kelly (2005) considera uma mudança no foco do sujeito epistêmico: de conhecedor individual para a ideia de comunidade de conhecedores que possuem práticas socioculturais derivadas de uma história em comum. Com isso, discute como essas considerações permitem a investigação de práticas epistêmicas voltadas à produção de argumentos científicos. Essas práticas sociais são constituídas de um conjunto de padrão de ações que será realizado por seus membros, enquanto compartilham objetivos, valores e significados. Essas práticas em que uma comunidade propõe, justifica, avalia e legitima enunciados para a construção de conhecimento são denominadas Práticas Epistêmicas (JIMÉNEZ-ALEIXANDRE et al., 2008; KELLY; DUSCHL, 2002; SANDOVAL, MORRISON; 2003; SANDOVAL; REISER, 2004).

Lemke (1997), ao dar ênfase à linguagem para o ensino de ciências, considera que a comunicação é um processo social. Assim, afirma que os professores pertencem a uma comunidade que fala a linguagem das ciências e que utiliza dessa linguagem para construir significados de uma maneira particular. Desse modo, podemos considerar que as Práticas Epistêmicas se tornam importante foco de estudos para analisarmos como os conceitos científicos são construídos e como os argumentos são utilizados para justificar alegações de professores em uma oficina de formação continuada.

Ao considerar as práticas sociais de produção do conhecimento dos estudantes, Jiménez-Aleixandre et al. (2008) propõem uma ferramenta analítica para as Práticas Epistêmicas. As práticas sociais em sua intrínseca relação com o saber foram divididas em Práticas Epistêmicas de Produção, Comunicação e Avaliação do conhecimento. Inspirados nas categorias propostas por Lidar, Lundqvist e Östman (2006), Silva (2011) analisou as conexões entre as ações dos professores e as Práticas Epistêmicas desenvolvidas na construção de conceitos científicos pelos estudantes. Segundo Nascimento, Silva e França (2012), para compreender o desenvolvimento das Práticas Epistêmicas dos estudantes durante o processo investigativo é importante que analisemos as ações dos professores. Essas ações referem-se às orientações dadas aos estudantes sobre o que conta como conhecimento relevante e as formas de adquiri-los. Assim, os Movimentos Epistêmicos são percebidos nas intervenções dos professores em atividades investigativas e são fundamentais para a construção dos conceitos científicos. Os aspectos epistêmicos na construção dos argumentos foram analisados por Ratz (2015); estes resultaram da análise da relação entre os Movimentos Epistêmicos e as Práticas Epistêmicas, com os argumentos de referência identificados na Sequência Didática Investigativa utilizada no estudo.

O papel do professor na argumentação em sala de aula foi estudado por De Chiaro e Leitão (2005). Para as autoras, os planos pragmático, argumentativo e epistêmico se relacionam com os papéis de alunos e professores na implementação da argumentação em sala de aula. Analisando a argumentação em grupos de discussão em sala de aula, um gerido por alunos, outro por professor, as autoras identificaram diferenças e similaridades. Os resultados apontam que, no plano pragmático, há similaridade entre os dois grupos, porém as atuações do professor apresentam uma maior variedade de ações verbais com foco na possibilidade de discussão do tema. No plano argumentativo houve similaridades também: argumentos e contra-argumentos foram formulados nos dois grupos. Já no plano epistêmico, houve uma maior diferença entre eles. Isso acontece nas ações que aproximam as falas dos estudantes aos conteúdos e formas de 
raciocínio próprias do campo do saber. No grupo de discussão gerido pela professora ocorreu o desenvolvimento dessas formas de raciocínio e também se conferiu o estatuto epistêmico às conclusões dadas.

Em outros estudos, Sasseron (2013) aponta a presença das esferas pedagógica e epistemológica da atuação do professor para o desenvolvimento da argumentação em sala de aula. Os propósitos pedagógicos estão relacionados com a criação de possibilidades para que os alunos, por meio de interações discursivas, realizem investigações e divulguem suas ideias no espaço e tempo de sala de aula. Já as ações epistemológicas estão ligadas à construção de um argumento científico. Com isso, características da investigação são trabalhadas, como a proposição de um problema, construção de dados, levantamento de hipóteses, reconhecimento e delimitação de variáveis e avaliação de ideias que vão sendo discutidas no processo. As esferas pedagógica e epistemológica permeiam uma a outra, tornando uma Sequência Didática Investigativa coerente com o propósito de construção de argumentos e de conceitos científicos. Consideramos importante analisar como é a relação entre as ações de quem conduz uma Sequência Didática Investigativa no desenvolvimento de dados dos argumentos.

\section{A argumentação na pesquisa de ensino de ciências e a construção de dados do argumento}

A linguagem argumentativa é uma das principais características da construção do conhecimento científico (SASSERON; CARVALHO, 2011). O compromisso com a avaliação de evidências e alegações na ciência faz com que a argumentação exerça um papel central na construção social do conhecimento (JIMÉNEZ-ALEIXANDRE, 2010). Para Scarpa e Trivelato (2012), a argumentação é objeto de pesquisas que buscam relacionar a linguagem e os contextos de aprendizagem com o ensino de ciências. Em aulas de ciências, a capacidade de avaliar modelos científicos está relacionada com a identificação de evidências que apoiam ou refutam informações científicas divulgadas nos meios de comunicação. Por relacionar dados à conclusão e auxiliar na identificação do papel das evidências na elaboração de afirmações, o Padrão de Argumento de Toulmin (2006) é uma ferramenta que permite compreender como ocorre a construção de argumentos em aulas de Ciências. Esse modelo é mostrado na Figura 1.

Figura 1. Padrão de Argumento de Toulmin

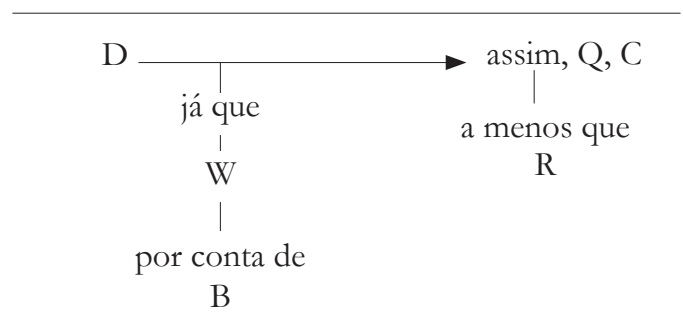

Legenda: D (Dados); C (Conclusão); W (Garantia); B (Apoio); Q (Qualificador Modal) e R (Refutação).

Fonte: Toulmin (2006). 
Toulmin (2006) desenvolveu um padrão de argumentos caracterizando seus elementos constitutivos e a relação entre eles. Os elementos constitutivos são: Dados: fatos a que recorremos para fundamentar nossa alegação; Conclusão: afirmações ou alegações cujos fundamentos buscamos estabelecer; Garantia: afirmações gerais que permitem a passagem dos dados à conclusão; Apoio: avais que conferem autoridade às nossas garantias; Qualificador: explicitam o grau de força que nossos dados dão à conclusão, levando em consideração a garantia; Refutação: explicitam os limites ou condições de exceção das garantias apresentadas.

Para Erduran (2007) uma das principais preocupações de quem pesquisa a argumentação em aulas de ciências é a metodologia. O Padrão de Argumento de Toulmin nos fornece a dimensão estrutural dos argumentos em termos de seus elementos: dados, conclusão, garantias, apoios e refutadores. Mesmo assim, há preocupação quanto à unidade de análise no que concerne a definir o que conta como dado, conclusão ou garantias. Toulmin (2006) não desenvolveu seus pressupostos originalmente para a área de educação. Entretanto, ao caracterizar as condições de passagem de dados à conclusão dos argumentos, esses pressupostos permitem estudar as formas como as pessoas avaliam os argumentos em diversos contextos, inclusive no ensino de ciências (DRIVER; NEWTON; OSBORNE, 2000).

Uma adaptação para a pesquisa foi feita por Erduran, Simon e Osborne (2004) que realizaram a junção de garantias e apoios do Padrão de Argumento de Toulmin, formando a justificativa do argumento. Outras adaptações foram realizadas, uma delas por Jiménez-Aleixandre, Reigosa Castro e Álvarez Pérez (1998) em que os itens do argumento foram especificados com relação ao tipo de dados, às informações e ao conhecimento básico, por diferenciação de justificativa simples e uma adaptação baseada em leis ou teorias, ou seja, o conhecimento de referência. A principal proposta na ampliação dos dados do Padrão de Argumento de Toulmin foi a elaboração de subcategorias baseando-se na natureza teórica ou experimental: dados fornecidos e dados obtidos. O primeiro grupo se refere aos dados de origem teórica, isto é, dados fornecidos pelo professor, livros textos ou roteiros de experimentos. Os dados de origem empírica são os dados obtidos, que podem ser classificados em dados empíricos (DE) e dados hipotéticos (DH). Tonidandel, Chernicharo e Trivelato (2009) analisaram os discursos de estudantes em aulas de Biologia em que investigavam a influência da luz no desenvolvimento vegetal. Os autores consideraram a categorização dos dados importantes para a análise dos dados empíricos, hipóteses, justificações e conhecimento básico durante a atividade investigativa. Para Sasseron e Carvalho (2014), os dados trabalhados em aulas de ciências podem ser empíricos e também produzidos em discussões deliberadamente planejadas.

Villani e Nascimento (2003) ampliaram a categorização realizada com relação aos dados de argumentos. Esses dados foram caracterizados como dados resgatados (DR), por estarem presentes no conhecimento prévio sobre um determinado assunto e trazidos para a discussão para servirem de base para uma conclusão. Para esses autores, o dado possui uma importância diferenciada para o Padrão de Argumento de Toulmin, quando aplicado a situações de sala de aula. Seus estudos versaram sobre o desenvolvimento de uma atividade experimental de Física, sendo que a categoria "dado resgatado" foi ampliada a partir de dado obtido, conforme ilustrado na Figura 2. 
Figura 2. Tipos de dados encontrados em ensino de ciências

Dado $\left\{\begin{array}{l}\text { Dado fornecido } \\ \text { Dado obtido }\end{array}\left\{\begin{array}{l}\text { Dado empírico } \\ \text { Dado resgatado }\end{array}\right.\right.$

Fonte: Villani e Nascimento (2003).

Uma ampliação da análise dos dados empíricos foi realizada por Motta e Motokane (2014). Os autores buscaram estabelecer como dados empíricos são vinculados ao argumento em textos individuais e coletivos produzidos por alunos em uma atividade de campo em Ecologia. Os dados empíricos foram divididos em duas categorias: os dados empíricos qualitativos (DEQL) e os dados empíricos quantitativos (DEQT). Os dados empíricos qualitativos se constituem em impressões ou observações da atividade de campo. Já os dados empíricos quantitativos se referem ao uso de números que resultaram das medições realizadas durante a saída a campo. Com isso, percebemos um esforço dos pesquisadores do ensino de ciências em estudar e ampliar as categorias de análise dos dados obtidos.

Apesar de ser um instrumento para análise de argumentação em aulas de Ciências, Driver, Newton e Osborne (2000) apontaram limitações do Padrão de Argumento de Toulmin para a pesquisa em situações de ensino. Uma das principais limitações é que o modelo de Toulmin apresenta a argumentação de uma forma descontextualizada, não considerando os aspectos interacionais do argumento. Com isso, considerando as limitações da análise da argumentação em aulas de ciências, propomos que analisar os aspectos epistêmicos nos permite ter uma visão mais ampla de como se dá o processo de construção de argumentos. Esse contexto de ensino e aprendizagem está relacionado com uma visão de conhecimento científico socialmente construído, desenvolvido com estudantes em uma perspectiva de aprendizagem que envolve processos individuais e sociais (DRIVER et al., 1994).

Em nosso estudo, interessamo-nos pelos aspectos sociais da aprendizagem em aulas de ciências para a análise da construção dos dados do argumento. Interessa-nos analisar os aspectos epistêmicos da construção dos dados fornecidos em uma Sequência Didática Investigativa em Ecologia aplicada a professores de Ciências e Biologia. As Sequências Didáticas Investigativas são sequências de atividades que se articulam, complementam e se complexificam para que diversos conteúdos sejam mobilizados para a resolução de problemas científicos contextualizados. Para Motokane (2015) as Sequências Didáticas Investigativas são pensadas considerando os objetivos de pesquisa em ciências, como também instrumentos de planejamento do ensino, estimulando os alunos a emitirem opiniões fundamentadas no conhecimento científico. Além disso, as Sequências Didáticas Investigativas apresentam os três pilares básicos dos pressupostos do ensino de ciências por investigação: a investigação, as interações discursivas e a divulgação de 
ideias (SASSERON, 2013). Por fim, tem como atividade comum em todas as etapas o trabalho com dados e evidências para a construção de argumentos científicos. Para análise de nossos dados utilizaremos o referencial de Movimentos Epistêmicos e Práticas Epistêmicas como apoio para análise das interações discursivas como um fenômeno influenciado pelo contexto em que o argumento está sendo produzido.

\section{O corpus desse trabalho}

Os dados desta pesquisa foram obtidos por meio de uma parceria entre o grupo de pesquisa $^{3}$ e uma Diretoria de Ensino do interior paulista no ano de 2012. Esta Diretoria de Ensino tinha como objetivo de formação de professores de Ciências e Biologia naquele ano letivo propiciar vivências inovadoras no Ensino de Ciências. A aplicação da Sequência Didática Investigativa teve duração de aproximadamente duas horas, para 25 professores de Ciências e Biologia. A oficina foi gravada e transcrita. Mesmo com a autorização dos participantes, elaboramos um sistema de numeração das falas do formador e dos professores para identificá-los na transcrição, sem utilizarmos os nomes verdadeiros. O formador e professores foram identificados na transcrição anteriormente à fala transcrita. Os professores foram identificados como Professor $n$, onde o $n$ é um número em sequência na identificação de cada professor na transcrição das falas. A Sequência Didática Investigativa que compõe o corpus desse trabalho foi produzida por Yamada e Motokane (2013) e trata da influência dos fatores abióticos em uma vegetação de Restinga.

O corpus desse trabalho foi analisado conforme a metodologia de Análise de Conteúdo (BARDIN, 1977). Com base nas unidades de registro e de contexto passamos para a contagem de frequência. Assim, transformamos os dados em agregados passíveis de serem descritos e analisados. Para tanto, analisamos cada episódio a partir de dois sistemas de categorias. A ideia de episódio é uma adaptação da definição de evento na tradição da etnografia interacional e se trata de um segmento do discurso com fronteiras claras em termos de conteúdo temático, tarefas desenvolvidas ou fase de atividades (MORTIMER et al., 2007).

\section{Nosso sistema de categorias}

Utilizaremos o sistema de categorias proposto para as Práticas Epistêmicas por JiménezAleixandre et al. (2008) para analisarmos as falas dos professores em formação. Assim como Lima-Tavares (2009) optamos por trabalhar com as Práticas Epistêmicas específicas e retirar as operações de textualização devido à sobreposição de categorias. As Práticas Epistêmicas são elementos discursivos envolvidos no processo de construção do conhecimento. As categorias das Práticas Epistêmicas são: Produção do Conhecimento, Comunicação do Conhecimento e Avaliação do Conhecimento. O Quadro 1 mostra nosso primeiro sistema de categorias.

\footnotetext{
${ }^{3}$ Grupo de Pesquisa Linguagem e Ensino de Ciências (LINCE) da Faculdade de Filosofia Ciências e Letras de Ribeirão Preto, Universidade de São Paulo, sob orientação do professor Dr. Marcelo Tadeu Motokane. 
Quadro 1. Sistema de Categorias para as Práticas Epistêmicas

\begin{tabular}{|c|c|c|}
\hline Categorias & Descrição & $\begin{array}{c}\text { Subcategorias } \\
\text { das Práticas Epistêmicas }\end{array}$ \\
\hline $\begin{array}{l}\text { Produção do } \\
\text { conhecimento }\end{array}$ & $\begin{array}{l}\text { Corresponde às ações dos estudantes nos } \\
\text { momentos iniciais de uma Sequência } \\
\text { Didática Investigativa ou quando constroem } \\
\text { hipótese, articulando seus conhecimentos } \\
\text { para isso. Além disso, a Produção } \\
\text { do Conhecimento está vinculada aos } \\
\text { movimentos discursivos de construção e } \\
\text { produção de sentido de dados. }\end{array}$ & $\begin{array}{l}\text { Problematizando; Elaborando } \\
\text { hipóteses; Planejando } \\
\text { investigação; Construindo dados } \\
\text { Utilizando conceitos para } \\
\text { interpretar dados; Articulando } \\
\text { conhecimento observacional e } \\
\text { conceitual; Lidando com situação } \\
\text { anômala ou problemática; } \\
\text { Considerando diferentes fontes de } \\
\text { dados; Checando entendimento; } \\
\text { Concluindo }\end{array}$ \\
\hline $\begin{array}{l}\text { Comunicação } \\
\text { do } \\
\text { conhecimento }\end{array}$ & $\begin{array}{l}\text { Corresponde aos movimentos discursivos } \\
\text { em que há interpretação e construção de } \\
\text { representações para transformar dados em } \\
\text { diferentes formatos e linguagens. Também } \\
\text { são identificados nas produções de textos que } \\
\text { circulam na aula e na persuasão dos pares. }\end{array}$ & $\begin{array}{l}\text { Apresentando ideias (opiniões) } \\
\text { próprias; Negociando } \\
\text { explicações; Usando linguagem } \\
\text { representacional; Usando } \\
\text { analogias e metáforas. }\end{array}$ \\
\hline $\begin{array}{l}\text { Avaliação do } \\
\text { conhecimento }\end{array}$ & $\begin{array}{l}\text { Corresponde aos movimentos discursivos } \\
\text { em que há coordenação entre dados, teoria } \\
\text { e evidência. Além disso, há a avaliação } \\
\text { das conclusões estabelecidas a partir das } \\
\text { evidências construídas. }\end{array}$ & $\begin{array}{l}\text { Complementando ideias; } \\
\text { Contrapondo ideias; Criticando } \\
\text { outras declarações; Usando dados } \\
\text { para avaliar teorias; Avaliando a } \\
\text { consistência dos dados. }\end{array}$ \\
\hline
\end{tabular}

Fonte: adaptado de Jiménez-Aleixandre et al. (2008).

Para analisarmos a fala do formador, utilizaremos o segundo sistema de categorias, os Movimentos Epistêmicos, proposto por Nascimento, Silva e França (2012). Abaixo elencaremos os Movimentos Epistêmicos.

Em nosso trabalho, a relação entre os Movimentos Epistêmicos mobilizados pelo formador e as Práticas Epistêmicas mobilizadas pelos professores resultará nos aspectos epistêmicos para a construção do argumento. Para tanto, identificamos o argumento de referência da Sequência Didática Investigativa. O argumento de referência foi utilizado no trabalho de Jiménez-Aleixandre, Bugallo Rodriguez e Dushl (2000) para a análise das operações argumentativas. Em nossa pesquisa, utilizamos o argumento de referência composto pelos itens do Padrão de Argumento de Toulmin para identificação de argumentos e posterior aplicação de nossos sistemas de categorias. O Quadro 2 mostra o Sistema de Categorias para os Movimentos Epistêmicos. 
Quadro 2. Sistema de Categorias para os Movimentos Epistêmicos

\begin{tabular}{|c|l|}
\hline $\begin{array}{c}\text { Movimentos } \\
\text { Epistêmicos }\end{array}$ & \multicolumn{1}{c|}{ Descrição } \\
\hline Elaboração & $\begin{array}{l}\text { Corresponde às ações do professor no sentido de possibilitar aos alunos, em geral } \\
\text { através de questionamentos, que construam um olhar inicial sobre o fenômeno. } \\
\text { São os questionamentos expressos nos roteiros de atividade ou mesmo proferidos } \\
\text { oralmente pelo professor, os quais geram espaço para que os alunos reflitam de } \\
\text { uma determinada perspectiva e exponham seus pontos de vista sobre os objetos e } \\
\text { eventos investigados. }\end{array}$ \\
\hline Reelaboração & $\begin{array}{l}\text { Corresponde às ações do professor no sentido de instigar os alunos, por } \\
\text { questionamentos ou breves afirmações, a observarem aspectos desconsiderados } \\
\text { ou a trazerem à tona novas ideias, favorecendo uma modificação, problematização } \\
\text { ou evolução do pensamento inicial apresentado. }\end{array}$ \\
\hline Instrução & $\begin{array}{l}\text { Corresponde à ação de apresentar explicitamente novas informações para os } \\
\text { alunos. }\end{array}$ \\
\hline Confirmação & $\begin{array}{l}\text { Corresponde à ação de concordar com as ideias apresentadas pelos alunos e/ou } \\
\text { permitir que eles executem determinados procedimentos planejados. }\end{array}$ \\
\hline Correção & $\begin{array}{l}\text { Corresponde à ação de corrigir explicitamente as afirmações e os procedimentos } \\
\text { dos alunos. }\end{array}$ \\
\hline Síntese & \begin{tabular}{l} 
Corresponde à ação de explicitar as principais ideias alcançadas pelos alunos. \\
\hline
\end{tabular} \\
\hline
\end{tabular}

Fonte: Nascimento, Silva e França (2012).

\section{Os argumentos de referência}

Apresentaremos os argumentos de referência no formato do Padrão de Argumento de Toulmin. Ressaltamos que não se trata de gabaritos a serem seguidos por quem conduz uma Sequência Didática Investigativa. $\mathrm{O}$ argumento de referência será um parâmetro em nosso trabalho para compararmos os argumentos construídos nas interações discursivas (JIMÉNEZALEIXANDRE; BUGALLO RODRÍGUEZ; DUSCHL, 2000).

A Sequência Didática Investigativa inicia com um trecho de um artigo retirado de um jornal de cunho científico que trata da elevação do nível do mar e das consequências para as cidades litorâneas. Em seguida é alertado o fato de que a maioria das notícias divulgadas sobre as consequências do avanço do mar enfatiza a destruição das cidades litorâneas. Assim, segue uma primeira questão que será discutida pelos participantes: será que a elevação do nível do mar pode trazer consequências para áreas não habitadas? A Sequência Didática Investigativa possui uma sessão denominada "Orientações pedagógicas para o uso das sequências didáticas". Por meio da análise das atividades propostas e das orientações dadas àquele que as conduzem, 
identificamos dois argumentos de referência. Dessa primeira etapa, identificamos o Argumento de Referência 1, mostrado na Figura 3.

Figura 3. Argumento de Referência 1 da Sequência Didática Investigativa

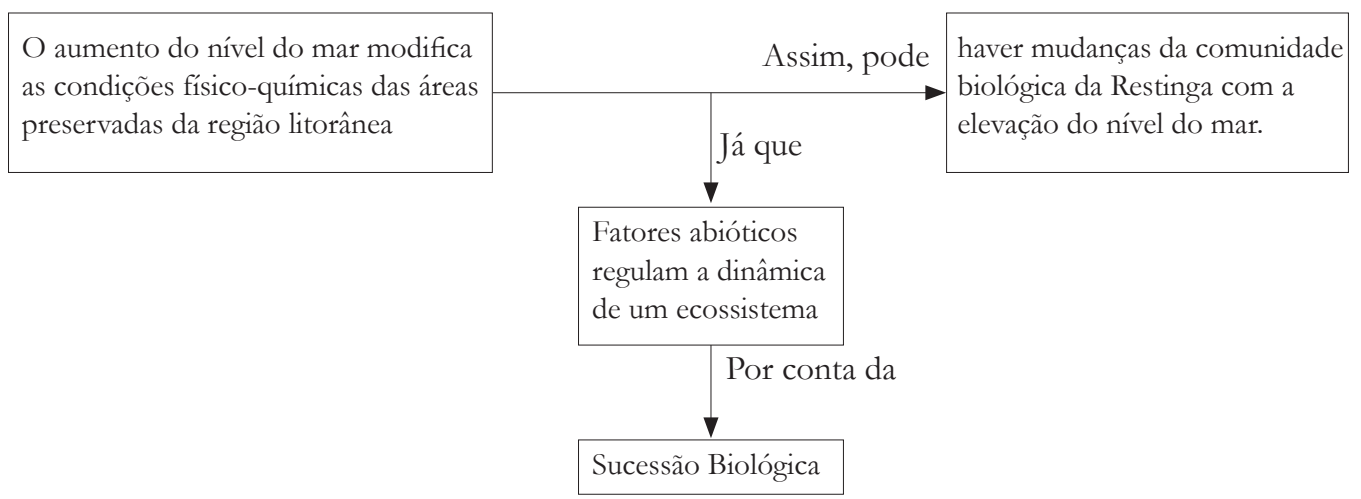

Fonte: elaborado pelos autores.

Logo após a socialização da primeira discussão, que se refere às consequências da elevação do nível do mar para as áreas preservadas, são trazidas as informações do material de apoio sobre as adaptações da vegetação da restinga. Após essa etapa, são exibidas as imagens do Núcleo Perequê da Ilha do Cardoso, sem indicar qual delas representaria o antes ou depois da elevação do nível do mar. Assim, foi solicitado aos professores que se reunissem novamente em grupos para discutirem qual figura representaria o antes e o depois, apresentando justificativas para a resposta com base no texto de apoio sobre as adaptações da vegetação da restinga. As instruções e encaminhamentos dessa segunda etapa compôs o Argumento de Referência 2, mostrado na Figura 4.

\section{Os episódios e os argumentos de referência}

Para estabelecermos os episódios neste trabalho, utilizamos como unidade de análise a fase de atividade. As fases de atividades podem ser decompostas em sequências de interação. Essas são compostas por turnos de fala que constituem a menor unidade de análise considerada neste trabalho e foram utilizados para a identificação das práticas epistêmicas e movimentos epistêmicos. Os argumentos de referência estabelecerão parâmetros para compararmos com os argumentos construídos. Os argumentos construídos são desenvolvidos ao longo das interações discursivas no desenrolar da Sequência Didática Investigativa. 
Figura 4. Argumento de Referência 2

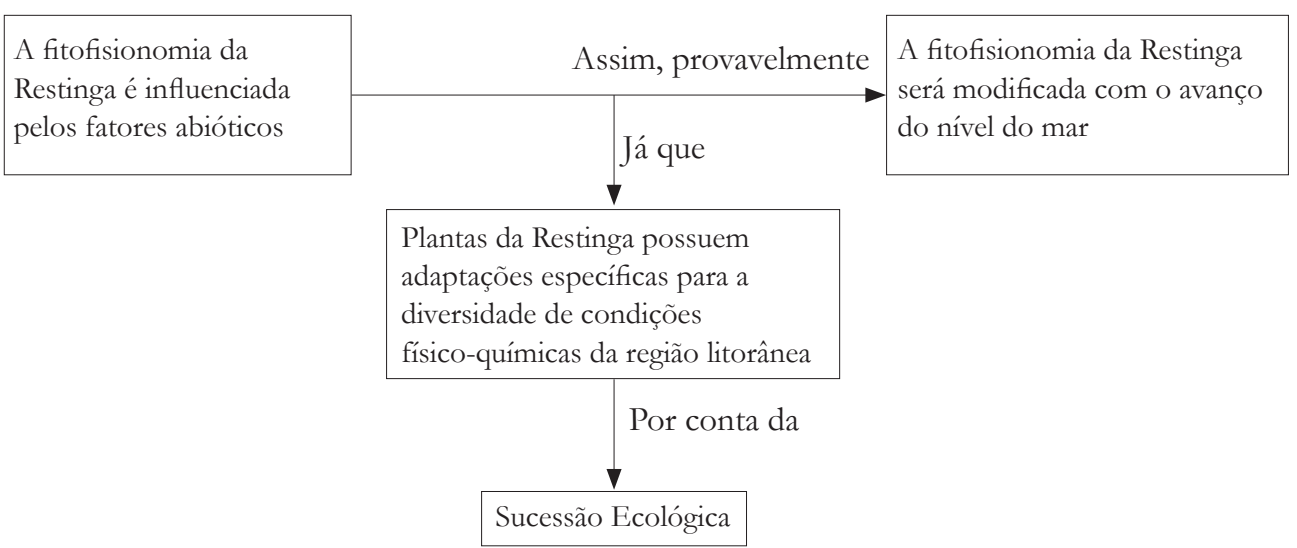

Fonte: elaborado pelos autores.

Com base nos Argumentos de Referência 1 e 2, identificamos duas fases de atividades gerais relacionados aos argumentos: Construção do Argumento de Referência 1 e Construção do Argumento de Referência 2. Cada Fase de Atividade foi delimitada por turnos de falas contidos em cada estratégia didática geral utilizada pelo formador no desenvolvimento da Sequência Didática Investigativa. Com os argumentos de referência conseguimos identificar, por meio dos turnos de fala e das estratégias didáticas nas Fases de Atividade, os Episódios que serão analisados por meio do sistema de categorias do nosso referencial teórico: Práticas Epistêmicas e Movimentos Epistêmicos. Os argumentos resultantes das interações discursivas, tendo como parâmetro os argumentos de referência, foram denominados argumentos construídos. Como nosso foco neste trabalho é a análise dos aspectos epistêmicos na construção de dados do argumento, analisaremos os episódios 1 e 4 . Esses episódios estão diretamente ligados à construção dos dados, conforme os argumentos de referência construídos por meio da análise da Sequência Didática Investigativa. Cada episódio apresentou uma dinâmica diferente para a construção dos dados dos argumentos que será discutida mais adiante. O Quadro 3 apresenta esse mapeamento dos Episódios 1 e 4 que serão analisados no presente trabalho.

Podemos observar que no Episódio 4 houve um maior investimento nas interações discursivas na construção dos dados do argumento, a partir dos dados fornecidos pela Sequência Didática Investigativa. Isso pode ser evidenciado por uma maior quantidade de turnos de fala no Episódio 4. Veremos a partir de agora como essas dinâmicas diferenciadas caracterizaram a construção dos dados do argumento a partir de dados fornecidos. 
Quadro 3. Mapeamento dos Episódios

\begin{tabular}{|c|c|c|l|c|}
\hline Atividade & $\begin{array}{c}\text { Fases de Atividades } \\
\text { (turnos) }\end{array}$ & $\begin{array}{c}\text { Quantidade de } \\
\text { turnos de fala }\end{array}$ & Descrição da Atividade & Episódios \\
\hline $\begin{array}{c}\text { Construção do } \\
\text { Argumento de } \\
\text { Referência 1 }\end{array}$ & $25-49$ & 24 & $\begin{array}{l}\text { Introdução ao tema e } \\
\text { apresentação da questão a } \\
\text { ser discutida. }\end{array}$ & 1 \\
\hline $\begin{array}{c}\text { Construção do } \\
\text { Argumento de } \\
\text { Referência 2 }\end{array}$ & $255-432$ & 178 & $\begin{array}{l}\text { Exposição oral e dialogada } \\
\text { e apresentação da próxima } \\
\text { questão a se discutida. }\end{array}$ & 4 \\
\hline
\end{tabular}

Fonte: elaborado pelos autores.

\section{O episódio 1: direcionamento na construção dos dados gerais.}

O episódio 1 inicia-se com a leitura de um texto de um jornal de cunho científico e traz dados referentes à elevação do nível do mar e às consequências para as cidades litorâneas. A seguir é realizada uma contextualização com duas fotos de áreas litorâneas. Uma imagem é da cidade de Santos com seus prédios próximos à orla. A outra imagem é de uma área preservada de Ubatuba. Ambas são localizadas no litoral do Estado de São Paulo. Além dessas duas imagens há uma imagem que retrata uma área urbana que foi danificada pelo mar. Em seguida é alertado o fato de que a maioria das notícias divulgadas sobre as consequências do avanço do mar enfatiza a destruição das cidades litorâneas. O formador segue com a Sequência Didática Investigativa realizando uma questão que será discutida pelos professores: será que a elevação do nível do mar pode trazer consequências para áreas não habitadas? O Quadro 4 mostra o resultado das frequências dos turnos em que foram identificadas as categorias epistêmicas Movimentos Epistêmicos e Práticas Epistêmicas - e as respectivas frequências de aparição encontrados no Episódio 1.

Quadro 4. Frequência de Aparição das categorias epistêmicas do Episódio 1

\begin{tabular}{|c|c|}
\hline $\begin{array}{c}\text { Frequência de Aparição dos Movimentos } \\
\text { Epistêmicos }\end{array}$ & $\begin{array}{c}\text { Frequência de Aparição das Práticas } \\
\text { Epistêmicas }\end{array}$ \\
\hline Instrução: $36,4 \%$ & Construindo dados: $100 \%$ \\
Elaboração: $27,2 \%$ & \\
Confirmação: $36,4 \%$ & \\
\hline
\end{tabular}

Fonte: elaborado pelos autores. 
No Episódio 1, percebemos que o formador apresenta um papel mais atuante nos momentos iniciais da Sequência Didática Investigativa. Isso pode ser evidenciado por uma maior quantidade de turnos em que foram identificados os Movimentos Epistêmicos do que aqueles identificados com as Práticas Epistêmicas. O Episódio 1 é caracterizado por um maior direcionamento dos dados. O Movimento Epistêmico de Elaboração apresentou uma característica de provocação do diálogo, auxiliando, desse modo, no levantamento de conhecimentos prévios e na construção das ideias iniciais da Sequência Didática Investigativa. Já os Movimentos Epistêmicos Instrução e Confirmação, também identificados no Episódio 1, apresentaram característica de direcionar a discussão para um determinado foco; neste caso, as alterações de áreas preservadas da região litorânea pelo avanço do nível do mar. A única Prática Epistêmica encontrada foi "Construindo dados" (100\%), relacionada à produção do conhecimento. Isso pode indicar que os momentos iniciais de uma Sequência Didática Investigativa são importantes para que o formador traga informações relevantes e confirmem as proposições dos professores. Trata-se de um momento de realizar questionamentos iniciais para que os professores possam construir os dados gerais do argumento construído a partir do Episódio 1.

O Quadro 5 apresenta trechos dos turnos de fala que exemplificam as análises realizadas no Episódio 1.

Quadro 5. Exemplo de turnos de fala do Episódio 1

\begin{tabular}{|c|c|c|}
\hline Turnos de fala & Transcrições das falas & Categorização \\
\hline 27 & $\begin{array}{l}\text { Formador: Esse é um tipo de notícia que, } \\
\text { com a qual já estamos acostumados. Então, a } \\
\text { pergunta que eu faço é... A mídia sempre dá um } \\
\text { enfoque para essas regiões populosas e com ênfase } \\
\text { na destruição das cidades ou das construçoes } \\
\text { humanas. Além das cidades o que mais pode ser } \\
\text { destruido nas faixas litorâneas? }\end{array}$ & Movimento Epistêmico: Elaboração \\
\hline 28 & Professor 2: Os mangues. & Prática Epistêmica: Construindo dados \\
\hline 29 & Formador: Os mangues! & Movimento Epistêmico: Confirmação \\
\hline 30 & Professor 2: As restingas? & Prática Epistêmica: Construindo dados \\
\hline 31 & Formador: Restingas... Mais? & Movimento Epistêmico: Confirmação \\
\hline 32 & $\begin{array}{l}\text { Formador: Então vamo lá, pessoal! O que tem } \\
\text { na região litorânea? }\end{array}$ & Movimento Epistêmico: Elaboração \\
\hline 33 & Professor 2: As praias? & Prática Epistêmica: Construindo dados \\
\hline 34 & Professor não identificado: As praias. & Prática Epistêmica: Construindo dados \\
\hline
\end{tabular}

Fonte: elaborado pelos autores. 


\section{O episódio 4: o trabalho com dados fornecidos e evidências}

No Episódio 4, o formador realizou exposição oral nesta etapa da Sequência Didática Investigativa. Este episódio inicia-se com a retomada de uma ideia discutida anteriormente: a modificação da comunidade biológica. O formador vai questionando o grupo de forma a direcionar o olhar dos professores para a vegetação da Restinga e suas adaptações. Com isso, constroem-se os dados do Argumento de Referência 2. Notamos que este episódio contou com 178 turnos de fala, quantidade bem maior que o Episódio 1. Além disso, houve a construção não somente dos dados, mas de outros itens do Padrão de Argumento de Toulmin.

Aqui temos um trabalho com as evidências. Para Sasseron e Carvalho (2014) as evidências podem ser obtidas a partir de experiências prévias, diferenciando-se dos dados pelo fato de não serem diretamente observáveis. As autoras apontam a necessidade de estudo dos dados para obtermos as evidências. Observamos em nossa pesquisa que o trabalho com dados fornecidos mobiliza as evidências que são construídas. As evidências, por sua vez, são construídas a partir da relação entre os dados fornecidos, com a garantia e com o apoio que estão sendo considerados nas discussões. Com isso, os mesmos dados que estão sendo trabalhados podem se desenvolver em conclusões diferentes, a partir das evidências que estão sendo consideradas. Assim, dados fornecidos podem requerer um investimento maior de quem faz a mediação em Movimentos Epistêmicos, como aconteceu no Episódio 4. Além disso, requerem a discussão dos itens do Padrão de Argumento de Toulmin, juntamente com os participantes da atividade. O Quadro 6 apresenta as Práticas Epistêmicas, os Movimentos Epistêmicos identificados no Episódio 4, suas respectivas frequências de aparição e os itens do argumento construídos.

Quadro 6. Frequência de Aparição das categorias epistêmicas do Episódio 2

\begin{tabular}{|c|c|c|c|}
\hline Episódios & $\begin{array}{l}\text { Frequência de Aparição dos } \\
\text { Movimentos Epistêmicos }\end{array}$ & $\begin{array}{l}\text { Frequência de Aparição das } \\
\text { Práticas Epistêmicas }\end{array}$ & $\begin{array}{l}\text { Itens do argumento } \\
\text { construído }\end{array}$ \\
\hline & $\begin{array}{l}\text { Elaboração: 52,90\% } \\
\text { Reelaboração: } 8,50 \% \\
\text { Confirmação: } 17,10 \% \\
\text { Correção: } 2,90 \% \\
\text { Síntese: } 2,90 \% \\
\text { Instrução: } 15,70 \%\end{array}$ & $\begin{array}{l}\text { Elaborando hipótese: } 5,50 \% \\
\text { Construindo dados: } 72,50 \% \\
\text { Utilizando conceitos para } \\
\text { interpretar dados: } 13,20 \% \\
\text { Articulando conhecimento } \\
\text { observacional e conceitual: } \\
3,30 \% \\
\text { Lidando com situação anômala } \\
\text { ou problemática: } 2,20 \% \\
\text { Checando entendimento: } \\
1,10 \% \\
\text { Apresentando ideias próprias: } \\
1,10 \% \\
\text { Complementando ideias: } \\
1,10 \%\end{array}$ & $\begin{array}{l}\text { Dados, } \\
\text { Conclusão, } \\
\text { Garantia e } \\
\text { Apoio do Argumento } \\
\text { de Referência } 2 .\end{array}$ \\
\hline
\end{tabular}

Fonte: elaborado pelos autores. 
Apesar de não se tratar de momentos iniciais da Sequência Didática Investigativa, essa atividade corresponde a iniciar a construção de um novo argumento que se relaciona com o Argumento de Referência 2. Neste episódio foi mobilizado o Movimento Epistêmico de Elaboração em 52,90\% dos turnos de fala do formador. Este contexto demandou que o formador realizasse questionamentos para que os professores refletissem sobre o ponto de vista dos objetos e eventos que estavam sendo investigados. Isso ocorreu principalmente em turnos em que estavam sendo levantadas as características de determinadas plantas da vegetação de Restinga, conforme exemplos de turnos de fala apresentados no Quadro 7. Nesse trecho o formador está levantando as características da vegetação da Restinga mais próxima à praia.

Os Movimentos Epistêmicos de Confirmação e Instrução foram importantes para direcionar o olhar dos professores e trazer novas informações a eles. O direcionamento do Movimento Epistêmico "Confirmação" foi caracterizado nos turnos em que o formador ratificava as falas em que os itens do argumento de referência estavam subjacentes. Consideramos que a confirmação dessas ideias foi importante no processo para a construção dos dados do argumento construído a partir do Episódio 4.

O Movimento Epistêmico de Reelaboração também teve um importante papel na condução das discussões em vista à construção desse argumento. $\mathrm{O}$ formador precisou realizar questionamento para que os professores considerassem a migração dos vegetais nas discussões. O Movimento Epistêmico de Síntese foi importante para o direcionamento dos dados do Argumento de Referência 2. O Movimento Epistêmico "Instrução" permitiu que o formador trouxesse informações explícitas sobre as características das adaptações de algumas espécies vegetais da Restinga. Isso ocorreu nos momentos em o formador solicitou que os professores lessem as informações que o material de apoio trazia. Com isso, consideramos que a garantia do argumento construído a partir do Episódio 4 foi construída por estar relacionada com as adaptações das plantas da Restinga. Essa dinâmica das interações discursivas no início da construção do argumento, a partir do Episódio 4, foi fundamental para a diferenciação entre os dados construídos no Episódio 1 e 4.

O Quadro 8 exemplifica as análises realizadas no Episódio 4, sobretudo com trechos em que o Movimento Epistêmico Reelaboração foi identificado. Essa nossa escolha se deve ao fato de considerarmos que esse Movimento Epistêmico foi uma importante ação do formador para a avaliação das ideias que estavam sendo discutidas pelos professores. Após o levantamento de hipótese realizado no turno 303, o formador confirma essa hipótese, que posteriormente será avaliada, e encaminha a sequência da atividade no turno 306.

\section{Algumas considerações acerca da construção dos dados do argumento fornecidos pelo material didático}

Para a construção dos dados de argumentos vimos que há mobilização de Movimentos Epistêmicos e Práticas Epistêmicas que se diferenciam dependendo da etapa da Sequência Didática Investigativa e da especificidade que o argumento requer. Os dados do argumento do Episódio 1 foram construídos de forma mais genérica, pois o Argumento de Referência 1 possui suporte teórico mais amplo, relacionado a uma condição de causa-efeito dos fatores abióticos na modificação de uma comunidade biológica. Assim, consideramos que essa foi a 
Quadro 7. Exemplos de turnos de fala

\begin{tabular}{|c|c|c|}
\hline Turnos de fala & Transcrições das falas & Categorização \\
\hline 329 & $\begin{array}{l}\text { Formador: Aqui? E aqui é mais rico? Vocês } \\
\text { deram diferença do solo, por exemplo. Então, } \\
\text { relacione isso pra mim à característica mais. } \\
\text { Como é, como, se o solo aqui é, como é o solo } \\
\text { aqui, então? Mais pobre. Mais arenoso ou } \\
\text { menos? }\end{array}$ & Movimento Epistêmico: Elaboração \\
\hline 330 & $\begin{array}{l}\text { Professores falando juntos ao mesmo } \\
\text { tempo: Mais. }\end{array}$ & $\begin{array}{l}\text { Prática Epistêmica: Articulando } \\
\text { conhecimento conceitual e } \\
\text { observacional }\end{array}$ \\
\hline 331 & $\begin{array}{l}\text { Formador: Mais arenoso. Se ele é arenoso, ele } \\
\text { armazena mais umidade ou menos? }\end{array}$ & Movimento Epistêmico: Elaboração \\
\hline 332 & $\begin{array}{l}\text { Professores falando juntos ao mesmo } \\
\text { tempo: Menos. }\end{array}$ & Construindo dados \\
\hline 333 & $\begin{array}{l}\text { Professores falando juntos ao mesmo } \\
\text { tempo: Mais. }\end{array}$ & Construindo dados \\
\hline 334 & Formador: Menos. Menos ou mais? & Movimento Epistêmico: Elaboração \\
\hline 335 & $\begin{array}{l}\text { Professores falando juntos ao mesmo } \\
\text { tempo: Menos. }\end{array}$ & Prática Epistêmica: Construindo dados \\
\hline 336 & Formador: Como é a vegetação para esse solo? & Movimento Epistêmico: Elaboração \\
\hline 337 & Professor 8: Mais baixa. & Prática Epistêmica: Construindo dados \\
\hline 338 & Formador: Mais baixa. & Prática Epistêmica: Construindo dados \\
\hline 339 & Professor não identificado: Rasteira. & Prática Epistêmica: Construindo dados \\
\hline 340 & Professor 3: Baixa? & Prática Epistêmica: Construindo dados \\
\hline 341 & $\begin{array}{l}\text { Professor 8: Tem uma, eu não lembro o nome } \\
\text { (inaudivel) dá característica mesmo. }\end{array}$ & Prática Epistêmica: Construindo dados \\
\hline 342 & Formador: Tem uma que é característica? & Movimento Epistêmico: Elaboração \\
\hline 343 & Professor 1: Raizes mais profundas? & Prática Epistêmica: Construindo dados \\
\hline 344 & Formador: Raizes mais profundas? & Movimento Epistêmico: Elaboração \\
\hline
\end{tabular}


Ratz, S. V. S.; Motokane, M. T.

Quadro 7. continuação

\begin{tabular}{|c|c|c|}
\hline Turnos de fala & Transcrições das falas & Categorização \\
\hline 345 & Professor 6: Não. & Prática Epistêmica: Construindo dados \\
\hline 346 & $\begin{array}{l}\text { Professores falando juntos ao mesmo } \\
\text { tempo: Não. }\end{array}$ & Prática Epistêmica: Construindo dados \\
\hline 347 & Professor 1: Não sei. & \\
\hline 348 & $\begin{array}{l}\text { Inaudível, pois vários professores falam } \\
\text { juntos ao mesmo tempo. }\end{array}$ & $\begin{array}{l}\text { Prática Epistêmica: Lidando com } \\
\text { situação anômala ou problemática }\end{array}$ \\
\hline 349 & Formador: Como é a raiz? & Sem categorização. \\
\hline 350 & $\begin{array}{l}\text { Professor 1: É mais (gesticulando com a } \\
\text { mão na horizontal). }\end{array}$ & Movimento Epistêmico: Elaboração \\
\hline 351 & Formador: Mais horizontal? & Prática Epistêmica: Construindo dados \\
\hline 352 & Professor 1: É. & Movimento Epistêmico: Elaboração \\
\hline 353 & $\begin{array}{l}\text { Professores falando juntos ao mesmo } \\
\text { tempo: É. }\end{array}$ & Prática Epistêmica: Construindo dados \\
\hline 354 & $\begin{array}{l}\text { Professor 2: Uma adaptação mais especifica, } \\
\text { né? Por conta dessa, da posição que ela ocupa } \\
\text { dentro do ambiente, tanto é que olhando aqui, } \\
\text { elas me parecem praticamente todos uma mesma } \\
\text { espécie. }\end{array}$ & Prática Epistêmica: Construindo dados \\
\hline 355 & $\begin{array}{l}\text { Formador: É. Daqui. Olhando dessa } \\
\text { distância. }\end{array}$ & $\begin{array}{l}\text { Prática Epistêmica: Utilizando } \\
\text { conceitos para interpretar dados }\end{array}$ \\
\hline 356 & Professor 2: Olhando assim. & $\begin{array}{l}\text { Movimento Epistêmico: Confirmação } \\
\text { Sem categorização. }\end{array}$ \\
\hline 357 & Formador: É. & Movimento Epistêmico: Confirmação \\
\hline 358 & $\begin{array}{l}\text { Professor 2: Essa primeira faixa de vegetais, é } \\
\text { por conta dessa característica de adaptação a essa } \\
\text { faixa, mais próxima, inclusive com característica } \\
\text { de ter maior tolerância pela salinidade. }\end{array}$ & $\begin{array}{l}\text { Prática Epistêmica: Utilizando } \\
\text { conceitos para interpretar dados }\end{array}$ \\
\hline
\end{tabular}


Quadro 8. Exemplos de turnos de fala

\begin{tabular}{|c|c|c|}
\hline Turnos de fala & Transcrições das falas & Categorização \\
\hline 297 & $\begin{array}{l}\text { Formador: Ao longo de, então, de novo } \\
\text { apareceu essa: ao longo do tempo essas (plantas) } \\
\text { vão sofrer modificacooes para se tornar melhor } \\
\text { adaptadas àquela área? }\end{array}$ & Movimento Epistêmico: Reelaboração \\
\hline 298 & $\begin{array}{l}\text { Professores falando juntos ao mesmo } \\
\text { tempo: Não. }\end{array}$ & \\
\hline 299 & $\begin{array}{l}\text { Inaudível, pois vários professores falam } \\
\text { juntos ao mesmo tempo. }\end{array}$ & \\
\hline 300 & $\begin{array}{l}\text { Professor 6: ... (inaudível). Não consegue } \\
\text { sobreviver ali porque o ambiente não é propicio } \\
\text { a isso. }\end{array}$ & $\begin{array}{l}\text { Prática Epistêmica: Utilizando } \\
\text { conceitos para interpretar dados }\end{array}$ \\
\hline 301 & Formador: Certo. & Movimento Epistêmico: Confirmação \\
\hline 302 & $\begin{array}{l}\text { Professor 6: Em algum momento elas estarão } \\
\text { (inaudível). }\end{array}$ & \\
\hline 303 & $\begin{array}{l}\text { Professor 2: E como a competição por alimento } \\
\text { vai ser muito intensa, os animais herbivoros vão } \\
\text { criar uma sobrecarga para aquela população de } \\
\text { vegetal que antes existiu ali. Agora vai ter muito } \\
\text { mais animais buscando alimentos, em termos de } \\
\text { herbivoros, que antes estavam distribuidos em } \\
\text { uma maior área. Então, a pressão sobre, é, os } \\
\text { vegetais que são utilizados como alimento por } \\
\text { grupos de animais sofrerão essa, vamos dizer } \\
\text { assim, essa, é, essa pressão ecológica que leva à } \\
\text { mudança, à modificação do próprio ambiente } \\
\text { no que dĩ respeito à comunidade. É, num } \\
\text { momento elas poderiam estar em maior número } \\
\text { e agora, por conta da pressão, em termos de } \\
\text { busca pela alimentaşão, deixarem de estar } \\
\text { num grupo, numa, numa condição numérica } \\
\text { menor. E assim vai havendo uma mudança na } \\
\text { comunidade como um todo. Aquelas árvores, por } \\
\text { exemplo, ou plantas que não são comestiveis, que } \\
\text { migraram por ali por conta de sementes serem } \\
\text { levadas passivamente pela água, de repente, } \\
\text { tomarem uma condição favorável pra crescer } \\
\text { e se desenvolver enquanto as outras que são } \\
\text { comestiveis por animais, perderem a sua, a sua } \\
\text { condição e aí começa a haver toda uma mudanca. }\end{array}$ & $\begin{array}{l}\text { Prática Epistêmica: Elaborando } \\
\text { hipótese }\end{array}$ \\
\hline
\end{tabular}


Quadro 8. continuação

\begin{tabular}{|c|l|l|}
\hline Turnos de fala & \multicolumn{1}{|c|}{ Transcrições das falas } & \multicolumn{1}{|c|}{ Categorização } \\
\hline 304 & Formador: Ok. & Movimento Epistêmico: Confirmação \\
\hline 305 & Professor 3: Tá? & $\begin{array}{l}\text { Formador: Bom. O que, o que eu vejo mais } \\
\text { frequente aqui é justamente a modificação de } \\
\text { fauna e flora e aí vou antecipar aqui. A partir } \\
\text { de agora nós daremos destaque à modificaşão da } \\
\text { flora. Agora sim, nós apresentaremos um texto } \\
\text { que fala um pouco mais da restinga. Então, eu } \\
\text { vou distribuir a primeira parte. Antes disso, } \\
\text { antes disso (dando direcionamento para a ordem } \\
\text { dos slides). }\end{array}$ \\
\hline
\end{tabular}

Fonte: elaborado pelos autores.

característica da construção de dados do argumento a partir de dados fornecidos pelo material didático: quanto mais amplo o suporte teórico, mais genéricos são os dados construídos.

Já os dados construídos no Episódio 4 foram mais específicos. O próprio Argumento de Referência 2 requer um suporte teórico mais específico por estabelecer uma relação entre a fitofisionomia da Restinga com as adaptações das plantas constituintes dessa região. Essa relação não é estabelecida a partir de relações de causa e efeito, mas a partir das propriedades das plantas dessa região que tenham sido favorecidas pela seleção natural. Essas propriedades permitem a distribuição diferenciada das plantas a partir das relações com o meio ambiente, tais como as condições climáticas e edáficas. Esse contexto demandou do formador maior variabilidade dos Movimentos Epistêmicos e Práticas Epistêmicas dos professores.

Nosso objetivo neste trabalho foi analisar quais os aspectos epistêmicos na construção do dado de um argumento a partir de dados fornecidos pelo material didático. Dessa forma, podemos ampliar os tipos de dados encontrados em situações de ensino de Ciências de Villani e Nascimento (2003), subdividindo e caracterizando os dados fornecidos pelo material didático. O Quadro 9 mostra a ampliação proposta.

É importante destacar que os dados fornecidos pelo material didático ou quaisquer outras fontes em uma Sequência Didática Investigativa não se constituem nos dados do argumento de forma automática. A importância de quem conduz a Sequência Didática Investigativa está em trazer os dados fornecidos para a discussão de modo que façam sentido e sejam construídos pela comunidade de aprendizes. Assim, a diferença dos Movimentos Epistêmicos do formador para a construção do dado do argumento construído a partir dos Episódios 1 e 4 pode ser explicada pela complexidade dos suportes teóricos envolvidos. 
Quadro 9. Características dos dados fornecidos pela Sequência Didática Investigativa

\begin{tabular}{|l|l|}
\hline Dados fornecidos & \multicolumn{1}{c|}{ Características } \\
\hline $\begin{array}{l}\text { Dados fornecidos } \\
\text { gerais }\end{array}$ & $\begin{array}{l}\text { Dados fornecidos nos momentos iniciais de uma Sequência Didática } \\
\text { Investigativa. Necessita de um suporte teórico de menor complexidade e de } \\
\text { conhecimento mais generalizado. }\end{array}$ \\
\hline $\begin{array}{l}\text { Dados fornecidos } \\
\text { específicos }\end{array}$ & $\begin{array}{l}\text { Dados fornecidos pela Sequência Didática Investigativa que requer um } \\
\text { conhecimento mais específico, com suporte teórico mais complexo e que } \\
\text { demanda maior conhecimento na área. }\end{array}$ \\
\hline
\end{tabular}

Fonte: elaborado pelos autores.

Como vimos, o Argumento de Referência 2 requer um suporte teórico mais específico. Isso demandou maior investimento do formador em Movimentos Epistêmicos de revisão de teorias, como Reelaboração e Correção. Já as Práticas Epistêmicas estão presentes nas três categorias: Produção, Comunicação e Avaliação do Conhecimento, o que indica uma relação com a variedade dos Movimentos Epistêmicos.

Um ponto que podemos destacar a partir dos resultados de nosso trabalho é a atenção necessária de quem conduz uma Sequência Didática Investigativa aos dados fornecidos pelo material didático e aos conhecimentos prévios da comunidade de aprendizes. Isso porque a diferenciação entre dados gerais e específicos está bastante ligada à complexidade do suporte teórico, porém mesmo argumentos mais simples poderão ser de difícil construção se aqueles que participam não estiverem habituados com as Sequências Didáticas Investigativas. Recomendamos para a área de pesquisa analisar a criticidade e interpretação dos contextos de produção dos dados fornecidos pelo material didático. Sendo assim, quem participa das Sequências Didáticas Investigativas precisa desenvolver mecanismos para analisar e avaliar os dados fornecidos, tais como autores, meios de comunicação, seus patrocinadores etc.

Por fim, teceremos algumas considerações acerca do contexto de coleta dos nossos dados: a formação continuada de professores. Carvalho e Gil-Pérez (2009) consideram que, apesar da formação inicial ser muito importante, revela-se cada vez mais a necessidade de estabelecer estruturas de formação coletiva continuada. Consideramos que nesses espaços permanentes de reflexão pode-se desenvolver a unidade teoria-prática, concretizada na práxis fundamentada na teoria e a ação docente a partir dela (CALDEIRA; ZAIDAN, 2013).

Para nós, o professor de Ciências é um professor de linguagem por considerarmos toda a semântica própria da área e suas peculiaridades na relação com o mundo natural (LEMKE, 1997). Almeida (2000) aponta que o fato de o professor se deter naquilo que dele se espera, sem considerar a concepção de ensino associada, é uma condição que não favorece uma mudança significativa no processo de ensino e aprendizagem. Sendo assim, consideramos importante que o professor se aproprie do seu papel enquanto um importante agente no desenvolvimento do raciocínio argumentativo e transformador da realidade e que essa apropriação seja acompanhada de uma reflexão crítica. 
Concordamos com Delizoicov, Angotti e Pernambuco (2009) que a atuação de professores e formadores não se reduz a domínios de práticas estabelecidas, mas que tais práticas precisam ser consideradas convenientemente em contextos ao se pretender ensinar conhecimentos específicos da área. Indicamos que os resultados deste trabalho podem compor referenciais teóricos para formação de professores de Ciências e Biologia. Ressaltamos, porém, que esse trabalho não seja visto isoladamente e que sejam considerados os demais aspectos e referenciais que dão o caráter complexo da formação dos professores de Ciências e Biologia como professores de uma linguagem própria - mas não exclusiva - das Ciências: o discurso argumentativo.

\section{Agradecimentos}

Os autores agradecem ao Grupo de Pesquisa Linguagem e Ensino de Ciências (LINCE) da Faculdade de Filosofia Ciências e Letras de Ribeirão Preto da Universidade de São Paulo (USP), bem como a todos os professores da Diretoria de Ensino participantes deste estudo.

\section{Referências}

ALMEIDA, M. J. P. M. Expectativas sobre desempenho do professor de física e possíveis conseqüências em suas representações. Ciência \& Educação, Bauru, v. 6, n. 1, p. 21-29, 2000. Disponível em: <http://dx.doi.org/10.1590/S1516-73132000000100003>. Acesso em: 13 out. 2016.

BARDIN, L. Análise de conteúdo. Lisboa: Edições 70, 1977.

CALDEIRA, A. M. S.; ZAIDAN, S. Práxis pedagógica: um desafio cotidiano. Paidéia, Belo Horizonte, v. 10, n. 14, p. 15-32, 2013. Disponível em: <http://www.fumec.br/revistas/ paideia/article/view/2374/1430>. Acesso em: 13 out. 2016.

CARVALHO, A. M. P.; GIL-PÉREZ, D. Formação de professores de ciências: tendências e inovações. 9. ed. São Paulo: Cortez, 2009.

DE CHIARO, S.; LEITÃO, S. O papel do professor na construção discursiva da argumentação em sala de aula. Psicologia: reflexão e crítica, Porto Alegre, v. 18, n. 3, p. 350-357, 2005. Disponível em: <http://dx.doi.org/10.1590/S0102-79722005000300009>. Acesso em: 13 out. 2016.

DELIZOICOV, D.; ANGOTTI, J. A.; PERNAMBUCO, M. M. Ensino de ciências: fundamentos e métodos. 3. ed. São Paulo: Cortez, 2009.

DRIVER, R.; NEWTON, P.; OSBORNE, J. Establishing the norms of scientific argumentation in classrooms. Science Education, Hoboken, v. 84, n. 3, p. 287-312, 2000.

DRIVER, R. et al. Constructing scientific knowledge in the classroom. Educational Researcher, Thousand Oaks, v. 23, n. 7, p. 5-12, 1994. 
ERDURAN, S. Methodological foundations in the study of argumentation in science classrooms. In: ERDURAN, S.; JIMÉNEZ-ALEIXANDRE, M. P. (Ed.). Argumentation in science education: perspectives from classroom-based research. [Berlim]: Springer, 2007. p. 47-69.

ERDURAN, S.; SIMON, S.; OSBORNE, J. TAPping into argumentation: developments in the application of Toulmin's argument pattern for studying science discourse. Science Education, Hoboken, v. 88, n. 6, p. 915-933. 2004.

JIMÉNEZ-ALEIXANDRE, M. P. 10 ideas clave: competencias en argumentación y uso de pruebas. Barcelona: Graó, 2010.

JIMÉNEZ-ALEIXANDRE, M. P.; REIGOSA CASTRO, C.; ÁLVAREZ PÉREZ, V. Argumentación en el laboratorio de física. In: ENCONTRO DE PESQUISA EM ENSINO DE FÍSICA, 6., 1998, Florianópolis. Atas... Florianópolis: SBF, 1998. 1 CD-ROM.

JIMÉNEZ ALEIXANDRE, M. P.; BUGALLO RODRÍGUEZ, B.; DUSCHL, R. A. "Doing the lesson" or "doing science": argument in high school genetics. Science Education, Hoboken, v. 84, n. 6, p. 757- 792, 2000.

JIMÉNEZ ALEIXANDRE, M. P. et al. Epistemic practices: an analytical framework for science classrooms. In: ANNUAL MEETING OF THE AMERICAN EDUCATIONAL RESEARCH ASSOCIATION, 2008, New York. Proceedings... Washington: AERA, 2008.

KELLY, G. J. Inquiry, activity, and epistemic practices. In: INQUIRY CONFERENCE ON DEVELOPING A CONSENSUS RESEARCH AGENDA, 2005, New Brunswick.

KELLY, G. J.; DUSCHL, R. A. Toward a research agenda for epistemological studies in science education. In: ANNUAL MEETING OF THE NATIONAL ASSOCIATION FOR RESEARCH IN SCIENCE TEACHING, 2002, New Orleans.

LEMKE, J. L. Aprender a hablar ciencia: language, aprendizaje y valores. Barcelona: Paidós, 1997.

LIDAR, M.; LUNDQVIST, E.; ÖSTMAN, L. Teaching and learning in the science classroom: the interplay between teachers' epistemological moves and students' practical epistemology. Science Education, Hoboken, v. 90, n. 1, p. 148-163, 2006.

LIMA-TAVARES, M. Argumentação em sala de aula de biologia sobre a teoria sintética da evolução. 2009. 296 f. Tese (Doutorado em Educação em Ciências) Faculdade de Educação, Universidade Federal de Minas Gerais, Belo Horizonte, 2009.

MORTIMER, E. F. et al. Uma metodologia para caracterizar os gêneros de discurso como tipos de estratégias enunciativas nas aulas de ciências. In: NARDI, R. (Org.). A pesquisa em ensino de ciência no Brasil: alguns recortes. São Paulo: Escrituras, 2007. p. 53-94.

MOTOKANE, M. T. Sequências didáticas investigativas e argumentação no ensino de ecologia. Ensaio: pesquisa em educação em ciências, Belo Horizonte, v. 17, n. especial, p. 155-137, 2015. Disponível em: <http://dx.doi.org/10.1590/1983-2117201517s07>. Acesso em: 13 out. 2016. 
MOTTA, A. E. M.; MOTOKANE, M. T. O uso de dados empíricos na construção de argumentos escritos em aulas de ciências naturais. Revista da SBEnBio, Niterói, n. 7, p. 420-431, 2014. Disponível em: < http://www.sbenbio.org.br/wordpress/wp-content/ uploads/2014/11/R0808-1.pdf>. Acesso em: 13 out. 2016.

NASCIMENTO, E. D. O.; SILVA, A. C. T.; FRANÇA, E. C. M. Práticas epistêmicas e movimentos epistêmicos de cada categoria, relacionando-as em uma atividade investigativa de ciências. In: COLÓQUIO INTERNACIONAL EDUCAÇÃO E CONTEMPORANEIDADE, 6., 2012, São Cristovão. Disponível em: < https:/ /ri.ufs.br/ bitstream/123456789/661/1/PraticasEpistemicasMovimentos.pdf>. Acesso em: 13 out. 2016.

RATZ, S. V. S. Os aspectos epistêmicos da construção de argumentos em uma sequência didática em ecologia. 2015. 199 f. Dissertação (Mestrado em Ensino de Ciências) - Universidade de São Paulo, São Paulo, 2015.

SANDOVAL, W. A.; MORRISON, K. High school students' ideas about theories and theory change after a biological inquiry unit. Journal of Research in Science Teaching, Hoboken, v. 40, n. 4, p. 369-392, 2003.

SANDOVAL, W. A.; REISER, B. J. Explanation-driven inquiry: integrating conceptual and epistemic scaffolds for scientific inquiry. Science Education, Hoboken, v. 88, n. 3, p. 345-372, 2004.

SASSERON, L. H. Interações discursivas e investigação em sala de aula: o papel do professor. In: CARVALHO, A. M. P. (Org.). Ensino de ciências por investigação: condições para implementação em sala de aula. São Paulo: Cengage Learning, 2013. p. 41-62.

SASSERON, L. H.; CARVALHO, A .M. P. Uma análise de referenciais teóricos sobre a estrutura do argumento para estudos de argumentação no ensino de ciências. Ensaio: pesquisa em educação em ciências, Belo Horizonte, v. 13, n. 3, p. 243-262, 2011.

. A construção de argumentos em aulas de ciências: o papel dos dados, evidências e variáveis no estabelecimento de justificativas. Ciência \& Educação, Bauru, v. 20, n. 2, p. 393-410, 2014. Disponível em: <http://dx.doi.org/10.1590/1516-73132014000200009>. Acesso em: 13 out. 2016.

SCARPA, D. L.; TRIVELATO, S. L. F. A linguagem e a alfabetização científicas: características linguísticas e argumentativas de artigos científicos. Genética na Escola, Ribeirão Preto, v. 7, n. 2, p. 46-57, 2012.

SILVA, A. C. T. Práticas e movimentos epistêmicos em atividades investigativas de química. In: ENCONTRO NACIONAL DE PESQUISA EM EDUCAÇÃO EM CIÊNCIAS, 8., 2011, Campinas. Anais... Campinas: ABRAPEC, 2011. Disponível em: <www.nutes.ufrj.br/ abrapec/viiienpec/resumos/R0660-1.pdf>. Acesso em: 16 dez. 2015. 
TONIDANDEL, S. M. R.; CHERNICHARO, P.; TRIVELATO, S. L. F. Atividade de análise de discurso de alunos em aulas de biologia do ensino médio. In: ENCONTRO NACIONAL DE PESQUISA EM EDUCAÇÃO EM CIÊNCIAS, 7., Florianópolis. Anais...

Florianópolis: ABRAPEC, 2009. Disponível em: < http://www.nutes.ufrj.br/abrapec/ vienpec/CR2/p738.pdf>. Acesso em: 16 dez. 2015.

TOULMIN, S. E. Os usos do argumento. 2. ed. São Paulo: Martins Fontes, 2006.

VILLANI, C. E. P.; NASCIMENTO, S. S. A argumentação e o ensino de ciências: uma atividade experimental no laboratório didático de física do ensino médio. Investigações em Ensino de Ciências, Porto Alegre, v. 8, n. 3, p. 187-209, 2003.

YAMADA, M.; MOTOKANE, M. T. Alfabetização científica: apropriações discursivas no desenvolvimento da escrita de alunos em aula de ecologia. Revista Práxis, Volta Redonda, v. 5, n. 10, p. 29-40, 2013. 